\title{
Metadata and Knowledge Management Driven Web-Based Learning Information System Towards Web/E-Learning 3.0
}

\author{
doi:10.3991/ijet.v5i2.1222 \\ H. Rego, T. Moreira, E. Morales and F.J. Garcia \\ University Of Salamanca, Salamanca, Spain
}

\begin{abstract}
AHKME e-learning system main aim is to provide a modular and extensible system with adaptive and knowledge management abilities for students and teachers. This system is based on the IMS specifications representing information through metadata, granting semantics to all contents in it, giving them meaning. Metadata is used to satisfy requirements like reusability, interoperability and multipurpose. The system provides authoring tools to define learning methods with adaptive characteristics, and tools to create courses allowing users with different roles, promoting several types of collaborative and group learning. It is also endowed with tools to retrieve, import and evaluate learning objects based on metadata, where students can use quality educational contents fitting their characteristics, and teachers have the possibility of using quality educational contents to structure their courses. The metadata management and evaluation play an important role in order to get the best results in the teaching/learning process.
\end{abstract}

Index Terms-e-Learning, Knowledge Management, IMS Specifications, Metadata Management.

\section{INTRODUCTION}

The Internet is constantly evolving, and nowadays we live times of change on the web with web 2.0, social networking and mass collaboration [1], even showing already some signs of what Tim Berners-Lee and guru Nova Spivak predicted as semantic web, intelligent web or in broader terms Web 3.0 [2].

One of the areas that is expanding in information technology lies in the implementation of systems or platforms for distance learning. Currently, there are many elearning systems, but the main difficulty lies in structuring the in line content and information with the existing learning models in order to achieve greater integration and comprehensiveness of the learning environment and by this providing better quality education. At the same time, yet there aren't too many tools and e-Learning systems for web/e-Learning 3.0, enabling the practical point of view or preparing to implement the semantic web, mobility of resources, as well as the universality of learning design, allowing teachers to approach the design process in an intuitive and practical way.

In order to address these needs in learning environments, information has to be perceived and processed into knowledge. One of the problems that have emerged from this transformation was how to represent knowledge. So standardization was indispensable, because it provides a semantic representation of the knowledge through ontologies in which concepts are clearly and unambiguously identified, providing a set of semantic relation types which allow representing meaning by linking concepts together [3][4].

Here we present AKHME a system that supports both knowledge representation and management based on metadata described by the IMS specifications, which goals and main contributions are: the learning object management and quality evaluation, where we tried to introduce some intelligence to these processes through intelligent agents; the usage of the IMS specifications to standardize all the resources of the platform; and the interaction of all subsystems through the feedback between them allowing the platform to adapt to students/teachers characteristics and to new contexts. As we know, the timely and correct management of knowledge became a sustainable source of competitive advantage, as well as a way to connect people to quality knowledge as well as people to people in order to peak performance. In the educational field, knowledge management and advanced systems can be used to explore how technologies can leverage knowledge sharing and learning and enhance performance [5][6]. We are trying to implement a system that adapts to students and teachers characteristics and to new contexts, using knowledge representation and management by capturing user behavior and interaction with the system, allowing decision makers to check which resources, course formats and learning strategies have best or worst results in determined contexts, helping them to define strategies on how to address certain types of students and contexts.

In this paper we will start to present the importance/impact of the called evolution to e-Learning 3.0, an analysis of standards and specifications in order to find the one to develop our system. We will give an overview and context the system and give main focus on the subsystems that provide learning objects management and quality evaluation through metadata. Finally we'll present some conclusions and future work.

\section{TOWARDS WEB/E-LEARNING 3.0}

While the concepts behind Web 2.0 are about social networking, like myspace [7], twitter [8], facebook [9] and orkut [10], and mass collaboration where the boundaries between authors and the users are slim. The concept behind Web 3.0 is slightly different, is based on web applications that provide value to the user through the usage of intelligent applications giving them a more 
accurate and precise information [11]. The idea behind this concept is that information should be available anytime, anywhere, anyhow, by this meaning that it should not only be available on common desktops but also in all types of devices that can somehow display web contents. This kind of concept raises the issue of interoperability where different devices and applications must interact with each other, allowing a freer environment for the final user. The main idea is to use technologies like XML, EDF, OWL, SPARQL, in order to standardize the information on the WEB so it can be readable by anyone, being seen as a global database, allowing this way the desired interoperability between systems.

Besides this, Web 3.0 aims a little further with the usage of 3D where services such as Second Life and the use of personalized avatars will be a common feature of the 3D web.

So the one of the main concepts behind Web 3.0 is the semantic, where using semantic technologies, and tolls powered with semantic understanding we can provide valuable information to the users.

As for e-Learning 3.0 the concepts aren't too distant from Web 3.0 concept since the all idea is to use all the potentiality of Web 3.0 on e-Learning.

According to Steve Wheeler e-Learning 3.0 will have at least four key drivers: Distributed computing; Extended smart mobile technology; Collaborative intelligent filtering; 3D visualization and interaction [12].

All these key drives meet the concepts behind Web 3.0.

e-Learning 3.0 aims to reach a wider range and variety of persons being available on different kinds of platforms/systems, through different tolls, where users will have the possibility to personalize their learning and have an easier access to comprehensive information. The usage of mobile technologies will certainly have a great impact in e-Learning 3.0, nonetheless the availability of tools, services, resources and support will also play an important role, since a new perspective of usage is being created.

This situation may turn e-Learning into a cross-social learning methodology since it will be possible to be applied in all contexts, making collaboration easier.

The 3D visualization devices will become more readily available, with interfaces like the ones, for example, provided by iPhone or Microsoft Surface, or even the use of $3 \mathrm{D}$ avatars.

\section{STANDARDS AND SPECIFICATIONS COMPARATIVE ANALYSIS}

In order to structure content and information using nowadays pedagogical models there has been the development of several standards and specifications like Sharable Content Object Reference Model (SCORM) [13], a project from Advanced Distributed Learning (ADL), which is a kind of a standard integrator, making it dependent of the standards it integrates, and the IMS specifications developed by the IMS consortium [14], that allows for example to structure the learning process, describe LOs through metadata, design learning units and courses, evaluate and characterize users.

The use of standards help to achieve more stable systems, reduces the development and maintenance time, allows backward compatibility and validation, increases search engine success, makes everything cross systems, among many other advantages [15].

In order to choose the specifications that would best fit our needs we started to analyze the support of several features, like described on Table I where we have analyzed the IMS Specifications, AICC, SCORM and Dublin Core [16], since several standards and specifications have been developed to structure pedagogical contents and to allow the characterization of a wide variety of learning environments [17].

From these standards and specifications we have analyzed, we have chosen the IMS specifications, since they allow most of the aspects we've analyzed and that we consider important to reach our goals.

\section{AHKME DESCRIPTION}

AHKME, represented on Fig.1, is an e-learning system that is divided in four different subsystems (Learning Object Manager and Learning Design, Knowledge Management, Adaptive, Visualization and Presentation subsystems), that were structured taking into account a line of reasoning, where first we have the process of learning objects creation and management, which is followed by the course creation process through the learning design. In parallel with these two processes the knowledge management (KM) subsystem evaluates the quality of the available learning objects and courses. Then they pass through an adaptive process based on the students' characteristics to be presented to them. A screenshot of the system frontend is presented on Fig. 2.

TABLE I.

STANDARDS AND SPECIFICATIONS COMPARATIVE ANALYSIS

\begin{tabular}{|c|c|c|c|c|c|}
\hline \multicolumn{2}{|l|}{ Features } & IMS & AICC & SCORM & Dublin Core \\
\hline \multicolumn{2}{|l|}{ Metadata } & $\checkmark$ & & $\checkmark$ & $\checkmark$ \\
\hline \multicolumn{2}{|c|}{ Learner Profile } & $\checkmark$ & & & \\
\hline \multicolumn{2}{|c|}{ Content Packaging } & $\checkmark$ & $\checkmark$ & $\checkmark$ & \\
\hline \multicolumn{2}{|c|}{ Question,Test \& Interoperability } & $\checkmark$ & & & \\
\hline \multicolumn{2}{|c|}{ DR Interoperability } & $\checkmark$ & & & $\checkmark$ \\
\hline \multicolumn{2}{|c|}{ Content structure } & $\checkmark$ & $\checkmark$ & $\checkmark$ & \\
\hline \multicolumn{2}{|c|}{ Content Communication } & & $\checkmark$ & $\checkmark$ & \\
\hline \multicolumn{2}{|c|}{ Learning Design } & $\checkmark$ & & & \\
\hline \multicolumn{2}{|c|}{ Accessibility } & $\checkmark$ & & & \\
\hline \multirow[t]{2}{*}{ Bindings } & XML & $\checkmark$ & & $\checkmark$ & $\checkmark$ \\
\hline & RDF & $\checkmark$ & & & $\checkmark$ \\
\hline \multicolumn{2}{|c|}{ Learner registration } & $\checkmark$ & & & \\
\hline
\end{tabular}




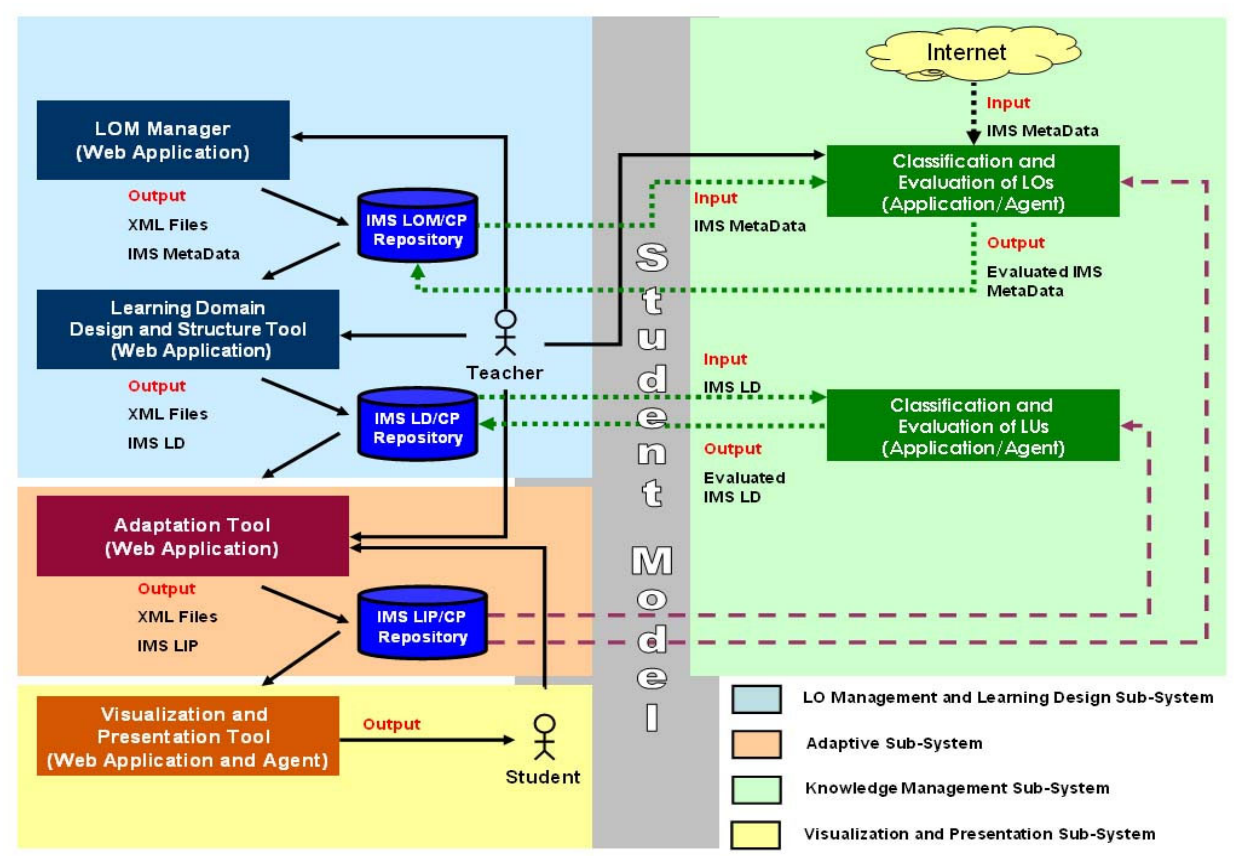

Figure 1. AHKME's structure

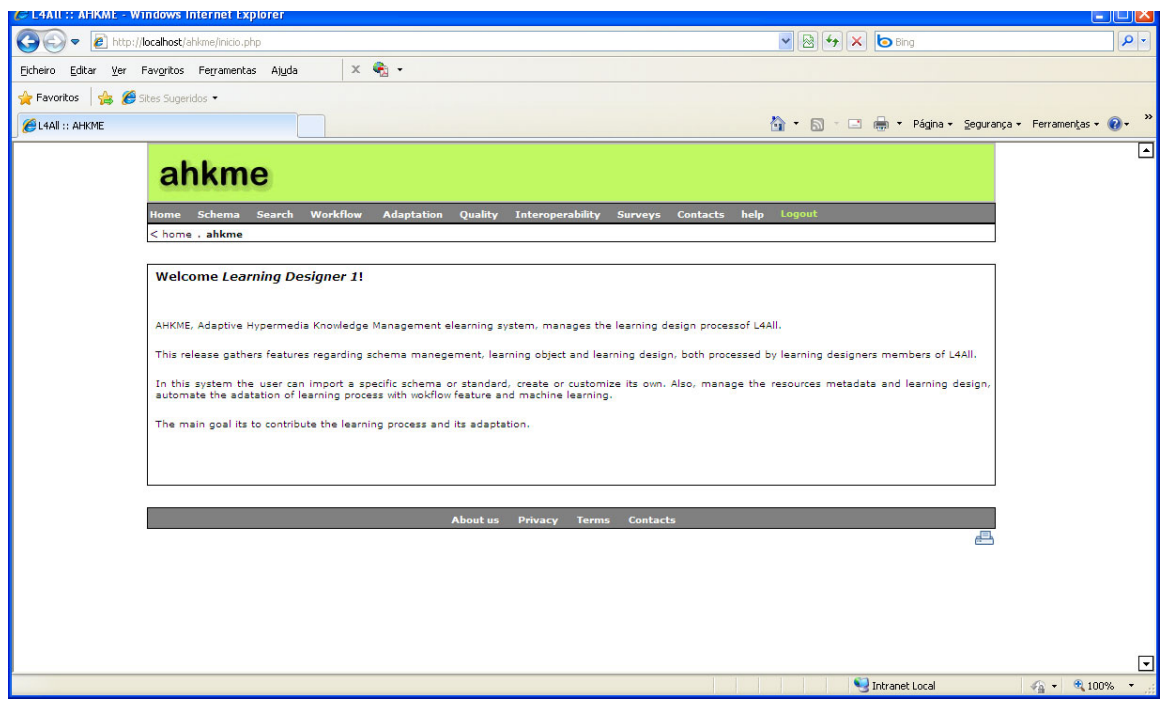

Figure 2. AHKME's front-end

We will now present the different subsystems that compose this system giving more focus on the components of the system that provide the management and evaluation of resources through their metadata, the Learning Object Manager and Learning Design subsystem and the Knowledge Management subsystem.

\section{A. Learning Objects Manager and Learning Design Subsystem}

This subsystem is mainly divided in two tools, the one that deals with LOs and the other that deals with the courses.

\section{1) Learning Objects Manager}

The Learning Objects (LO) Manager tool allows teachers to define/create metadata to describe Los sing the IMS Learning Resource Metadata (IMSLRM) specification [14] that is based on the IEEE LOM standard allowing the KM / representation through LOs [18]. Its architecure is shown on Fig. 3.

This tool allows to edit LOs and associate descriptive metadata to them, we can see a layout of the tool on Fig, 4. The system passes the information into a XML manifest that gathers all the XML files with their metadata and all the resources used by a learning object. Besides it has an information packaging feature that gathers their manifests with the LOs and their stores them in a MySQL database, what enables the management of these packages that will be used in the design of courses. The information packaging enables the creation of packages of LOs and courses with their metadata, so they can easily be transported and reused in other systems, going towards reusability and interoperability, using the IMS Content Packaging (CP) specification [19]. 


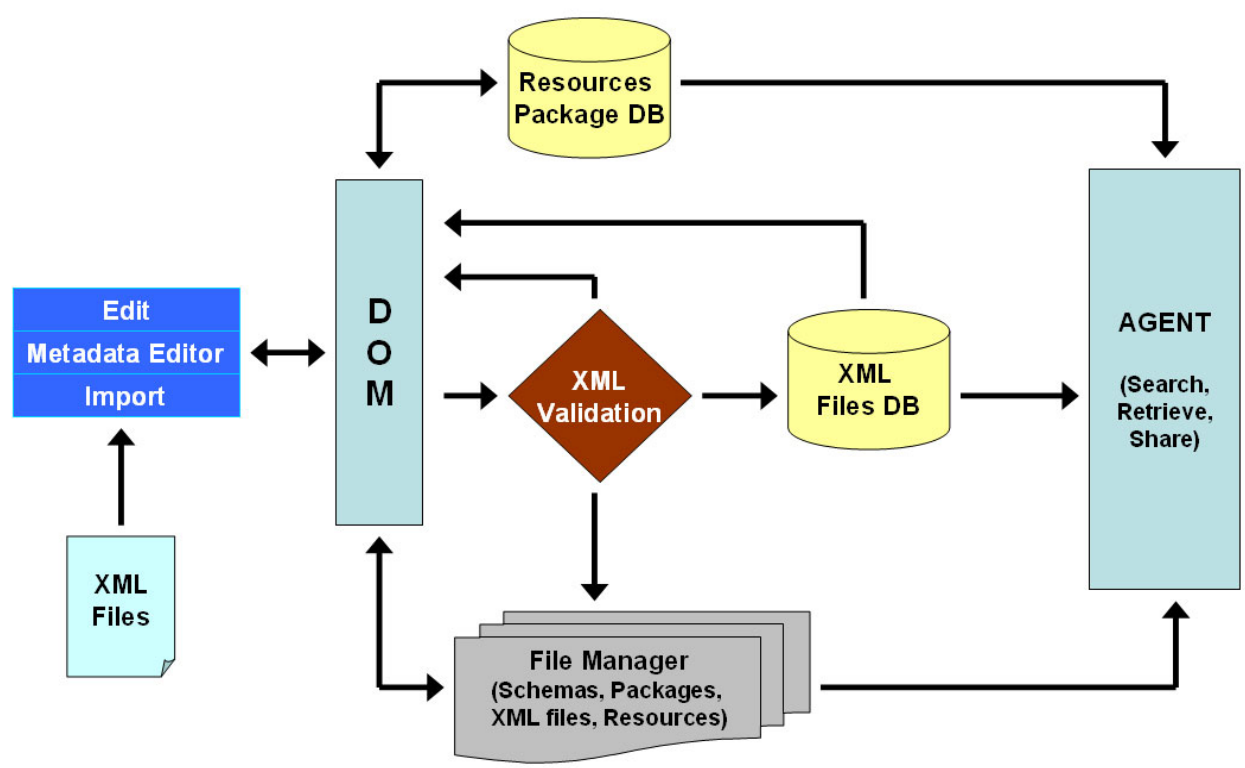

Figure 3. Learning Object Manager Architecture

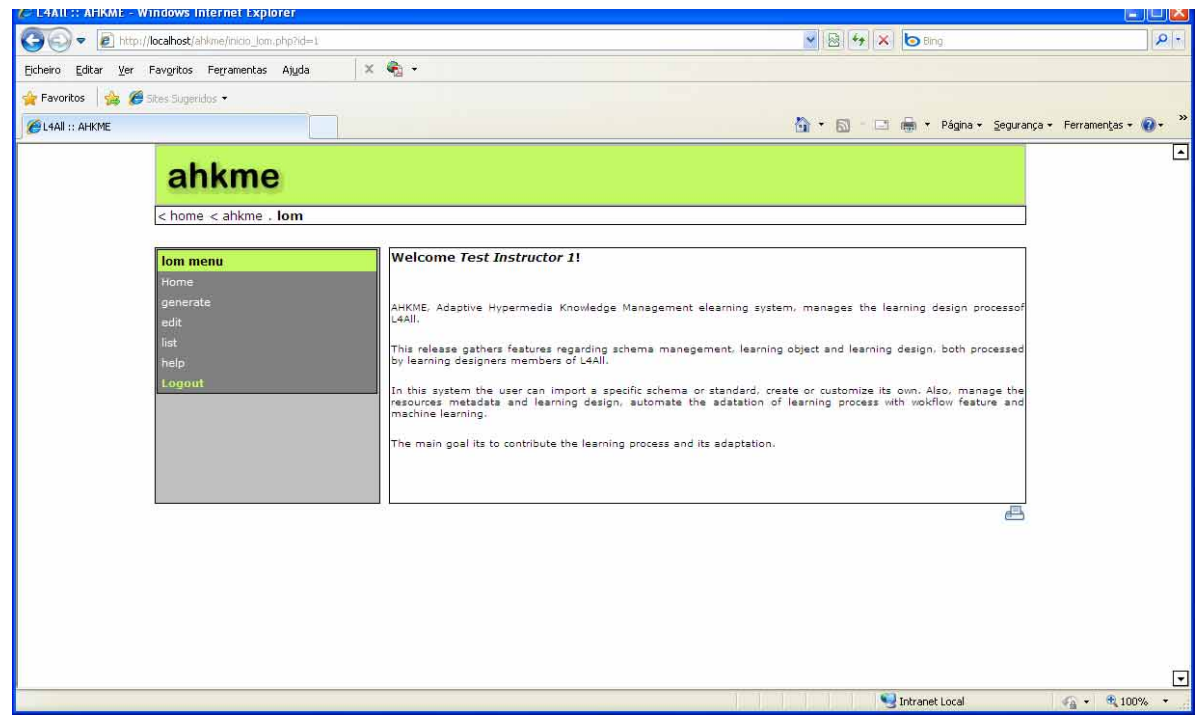

Figure 4. AHKME platform - Learning Objects Manager tool

All the files and packages in the platform pass through a validation process to check if they're in conformance with the IMS specifications, and all the communication between tools and databases is done through XML Document Object Model.

The learning objects are in constant evaluation made by the knowledge management subsystem that has tools that communicate with the learning object Manager.

The main advantage of using the IMS specification for learning objects is that through the association of descriptive tags, we can better index them, find them, use and reuse them.

In order to facilitate the insertion of metadata we provide an automation feature of this process, advising the most commonly used values for the elements on the learning objects cataloguing in order to describe them through the most adequate metadata elements.
In order to better search and retrieve LO's this subsystem is endowed with a search engine, since one of the most common problems that teacher face are how to locate, select and semantically relate suitable learning resources [20].

The search of LOs is a very important task in order to reach reusability, going towards the so long desired sustained and continuous improvement of learning resources, with an emphasis on the use and reuse of dynamic, relevant, and high quality materials over time [21]. The descriptive metadata associated to LOs becomes now more important than ever.

The search engine is based on an intelligent agent that receives as inputs the metadata elements from IMSLRM [22] for their search and retrieval.

When the teacher accesses the LO search engine, he can choose from two different types of search - simple or advanced. If the teacher chooses a simple search the agent 
automatically presents the metadata elements mostly used in searches for him to fill. This metadata fields may vary depending on the frequency in which they are used. Otherwise, if the teacher chooses an advanced search, he may choose whatever elements he wants to search for. Finally, the search engine, presents the LOs according to the teacher's search query with the respective quality evaluation allowing him to choose the LOs with more quality to integrate the courses he is creating.

\section{2) Learning Design Tool}

The part of the subsystem referring to the Learning Design provides a tool where teachers can define learning design components, create and structure courses using level A of the IMS Learning Design (LD) specification to define activities, sequence and users' roles, and to define metadata to describe the courses, making possible the knowledge representation of the courses like described on Fig. 5 [23].

In the process of course creation an XML manifest is generated gathering all the XML files associated with the course, as well as all the LOs, metadata and resource files needed for the course.

The platform, through this tool, allows the design of learning units where the participants can assume different roles. These roles can be student or staff, what makes possible collaborative and group learning, which importance is recognized at the training and educational levels [24].

The use of the IMS LD allows the users to structure courses with metadata in XML files that can be reused in the construction of other courses making easier the portability of learning information to interact with Learning Management Systems (LMS).

This tool also provides the creation of packages with the courses that are also stored in a data repository, to reach a more efficient management and communicates with the knowledge management subsystem in order to evaluate the courses. After the evaluation this tool allows the restructuring of courses allowing the user to interact with the LD process.

\section{B. Knowledge Management Subsystem}

We live in a society where there is a huge amount of information, but we must know which is more important to us and we must know how to manage it in order to get knowledge. Knowledge management is one of the biggest sources of power in our society, because it enables people with the power to manage information in order to extract knowledge to get accurate information for decision making, being one of the main priorities for the survival of organizations.

Knowledge management and e-learning are two concepts that are strictly related, as e-learning needs an adequate management of educational resources to promote quality learning, to allow students to develop in an active and efficient way, needing to make content quality evaluation systematic evaluation a valued practice if the promise of ubiquitous, high quality Web-based education is to become a reality [25].

The knowledge management features on an educational environment are presented by Bates, that points the requirements of e-learning independently from the location where you're at: access to information from multiple resources and formats; select, store, restructure and create information; communicate directly with instructors, colleagues and other students; incorporate materials that have already been worked within a study work documents and share and manipulate information, documents, projects, etc [26].

Taking this into account we have decide to create a subsystem which main objective is to assure quality to the information in the platform through the evaluation of LOs and courses, to get the best courses and the best resources to reach to the best learning/teaching process.

\section{1) Learning Objects Evaluation}

To achieve a learning object's optimal evaluation, it is necessary to consider quality criteria, for this reason the weighted criteria presented in Table II were proposed [27] where the final evaluation value is the sum of all the classifications of each category multiplied by their weight and has the following rating scale: $0=$ not present; $1=$ Very low; 2=Low;3=Medium;4=High;5=Very High. To use these criteria we have made a match between the IMSLRM educational category elements and the categories described on Table II. For now we have just considered the educational category because it has most of the learning objects technical and educational aspects we found important to evaluate.

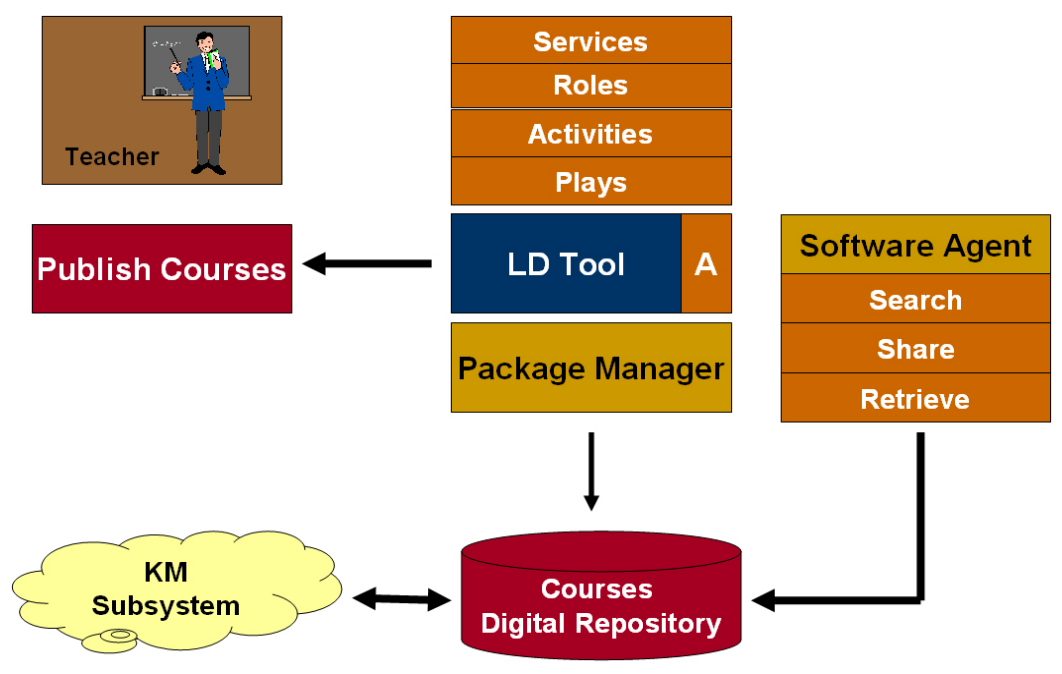

Figure 5. Learning Object Manager Architecture 
With these criteria, we're developing two different tools to evaluate learning objects quality. One tool allows teachers and experts to analyze, change and evaluate learning objects through a Web application and after the individual evaluation, all persons involved gather in a sort of online forum to reach to the learning object final evaluation [27].The other tool is an intelligent agent that automatically evaluates learning objects basing its final evaluation on previous evaluations. A schematic representation of the agent is presented on Fig. 6.

The agent acts when some kind of interaction is made on the LOs in order to readjust its quality evaluation. For example, if students have difficulties in using a LO, the quality evaluation will be recalculate in order to reflect them. Thus, the agent starts to import the learning object to evaluate and others already evaluated, then applies data mining techniques (decision trees) to its educational characteristics defined in the IMSLRM specification to calculus its final evaluation.

With these tools learning objects are constantly being availed of their quality, playing an important role in the learning objects reusability for different contexts. Meanwhile we are testing these tools in order to verify their reliability.

\section{Adaptive Subsystem}

The objective of this subsystem is to determine the most adequate learning method according to students' characteristics, the learning design and the interaction with the student. It establishes the best adaptive characteristics taking into account a specific learning method of the student, resources and assessments. This subsystem, for each student, stores his learning style, his characteristics, previous and actual knowledge.

The tool provided by this subsystem allows the user to fill inquiries, based on data and metadata about the student, defined by the IMS Learning Information Package (LIP) specification like described on Fig. 7

The IMS LIP specification is based in a data model to represent knowledge that describes the characteristics (language, previous and actual knowledge about a certain matter, etc) of the students, necessary for general management and storage of historical data about learning, objectives and works developed [28][29]. Based on the results of the inquiries an agent automatically generates adaptive rules, through the use of fuzzy logic, to generate models of adaptation that will reflect on the presentation of the courses. This information is stored in XML files and this subsystem allows the creation of packages with this information, which is stored in a data repository to facilitate its management [30]. These adaptive systems along with knowledge management system can provide information for teachers to rethink the content and structure of their courses and resources, and helps them customize the courses to the students' needs [31].

We have also introduced some collaborative tools, like a workflow tool like shown on Fig. 8, and the usage of intelligent agents for provisioning and sharing resources and learning strategies, recommending adaptations in learning resources.

TABLE II.

EVALUATION CRITERIA CATEGORIES AND MATCHING WITH THE IMSLRM EDUCATIONAL CATEGORY

\begin{tabular}{|l|c|l|l|}
\hline Evaluation criteria categories & Weight & \multicolumn{1}{|c|}{ IMSLRM Ed. Elements } & \multicolumn{1}{|c|}{ Description } \\
\hline Psychopedagogical & $30 \%$ & $\begin{array}{l}\text { intended end user role; typical age range; } \\
\text { difficulty }\end{array}$ & $\begin{array}{l}\text { Criteria that can evaluate, for example, if the } \\
\text { learning object has the capacity to motivate the } \\
\text { student for learning. }\end{array}$ \\
\hline Didactic-curricular & $30 \%$ & $\begin{array}{l}\text { learning-resource type; context; typical } \\
\text { learning time; description }\end{array}$ & $\begin{array}{l}\text { Criteria to evaluate if the learning object helps to } \\
\text { archive the unit of learning objectives, etc. }\end{array}$ \\
\hline Technical-aesthetic & $20 \%$ & semantic density; language & $\begin{array}{l}\text { Criteria to evaluate the legibility of the learning } \\
\text { object, the colors used, etc. }\end{array}$ \\
\hline Functional & $20 \%$ & interactivity type; interactivity level & $\begin{array}{l}\text { Criteria to evaluate learning objects accessibility } \\
\text { among other aspects to guarantee that it doesn't } \\
\text { obstruct the learning process. }\end{array}$ \\
\hline
\end{tabular}

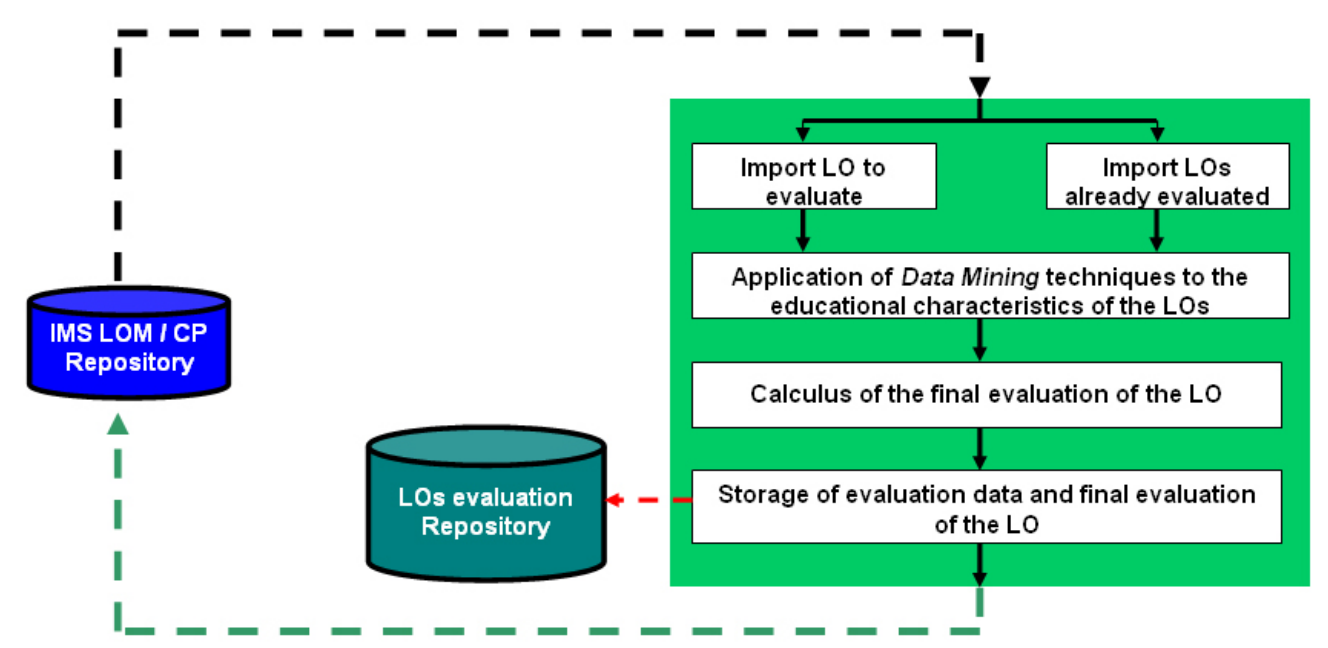

Figure 6. Learning Object Manager Architecture 


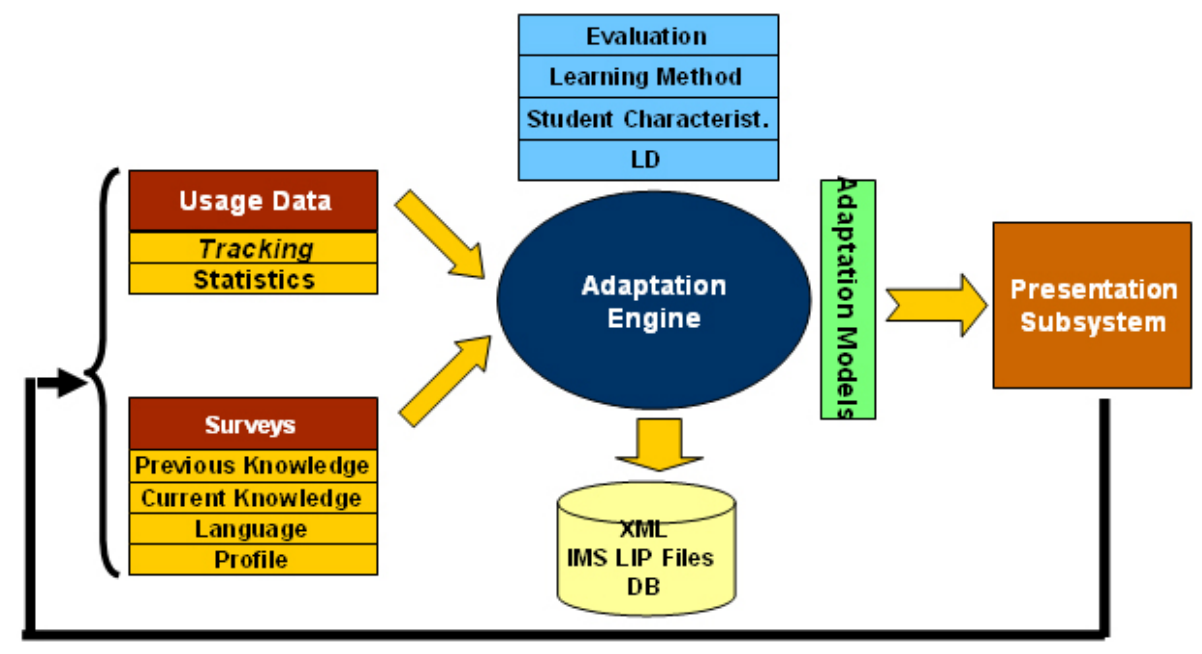

Figure 7. Adaptive Tool Architecture

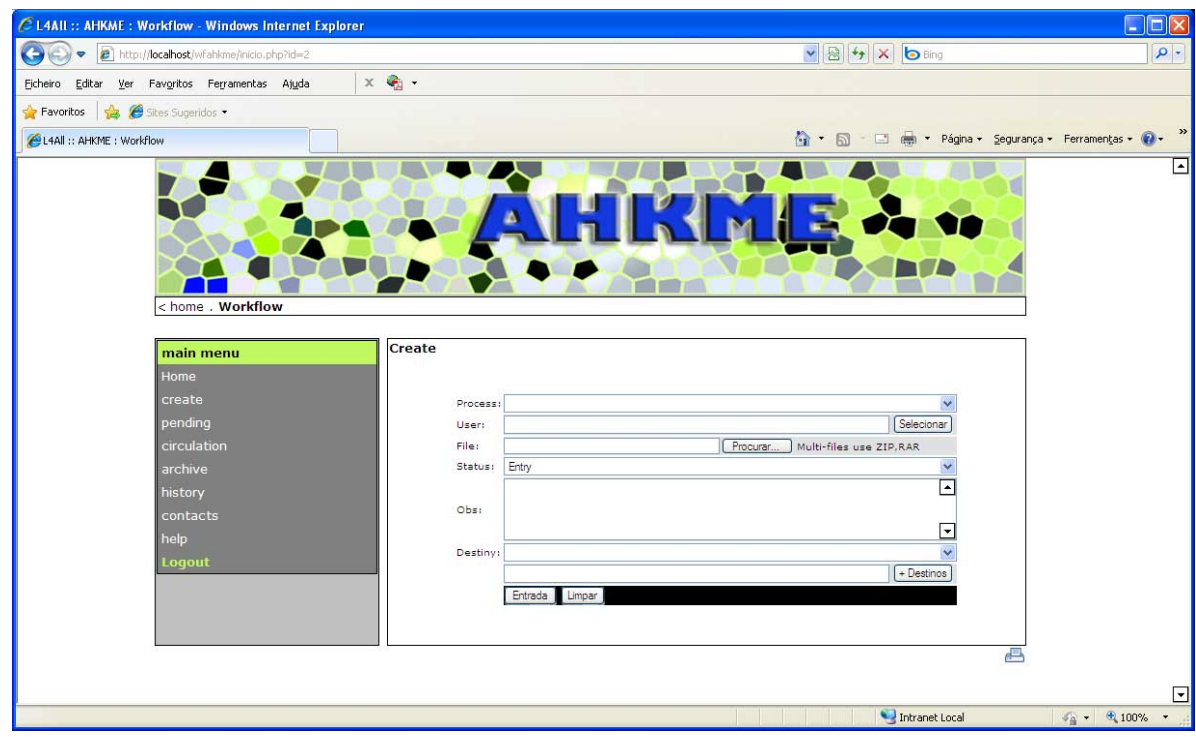

Figure 8. Workflow process.

\section{Visualization and Presentation Subsystem}

This subsystem presents the educational contents to the students taking into account the adaptive meta-model generated for each student.

This subsystem is where is defined the integration with LMSs and Social Networking Systems, front-end to the students. The objective for this integration is to give an opportunity for LMSs/social networking systems to benefit from AHKMEs' functionalities, as well as to give a front-end to AHKME system.

This integration can be done in different ways: In case of Moodle being developed in PHP and with a MySQL database, it can be directly integrated into the LMS; In other cases it can be done through a specific profile in the LMS that gives access to this Back-Office to a Course Instructor and Designer; If we want to integrate with some commercial platform like Blackboard or WebCT (currently Blackboard Learning System), it can be done, through a plug-in like a Powerlink (WebCT) or a building block (Bb); It always gives the possibility of integrating the courses by importing it to the LMS that supports the IMS specifications.
An agent can be developed in order to register the feedback of students and teachers regarding course usage, using the IMS LIP specification, so this information feeds the adaptive subsystem in order to be considered on the LD process in similar contexts.

This subsystem also gives a front-end to our system, combining tools from different platforms, collaborative, interactive, communication and community tools.

\section{DATABASES AND METADATA MANAGEMENT}

With the increasing volume of information, databases and database management have become indispensable in every organization or enterprise in order to acquire timely and accurate data about operations, to manage data effectively, and to use this data for analyzing requirements and controlling activities. Database management continues to gain importance, as more and more data is being made online and easily accessible through computer networking. In e-learning, with the massive creation of resources and courses, databases have become as important as in the commercial world where administrators, developers, teachers and students demand the same kind of accuracy. 
Some of the advantages that databases bring to teachers, students, managers and developers of e-learning systems are as follows [32].

- In authoring and managing learning resources, because resources can easily be manipulated, inserted and retrieved from a database so they can be searched, retrieved and reused.

- In the development of runtime delivery engines, since you can store the whole structure of a course in a database reducing this way the time and costs of developing and delivering new courses.

- Help students to monitor their performances, since all the information about the student and all the assessments he makes can be stored in databases, allowing him to see if he is reaching his objectives.

- And of course to course/learning management systems, since databases are used in a CMS or LMS to store all the information about the agents that interact with it as well as the information about resources and courses.

So, by this mean AHKME uses databases to manage metadata of the resources and also files in the way it's represented on Fig. 8. Databases work in this platform as a way to represent all the XML files generated by the platform, schemas and personalized schemas, packages of information, metadata resources, etc. To support these representations we have created the repositories depicted in Figure 9:

- XML files DB: This repository is a database with all the information about all the XML files and metadata that have been created or modified by AHKME or that has been created by other XML tools and have been imported in this repository.

- Resources Package DB: This repository is a database containing all the information about the packages of resources that have been created or modified by AHKME or that have been created by other systems and have been imported in this repository.

- Files system manager: This repository is a system file containing all the educational metadata files of XML type, schemas and physical resources files that have been created or modified by AHKME or have been created by other tools and have been imported in this repository, allowing the management of all these files.

All the tools in the system interact with the databases using the XML Document Object Model (DOM).

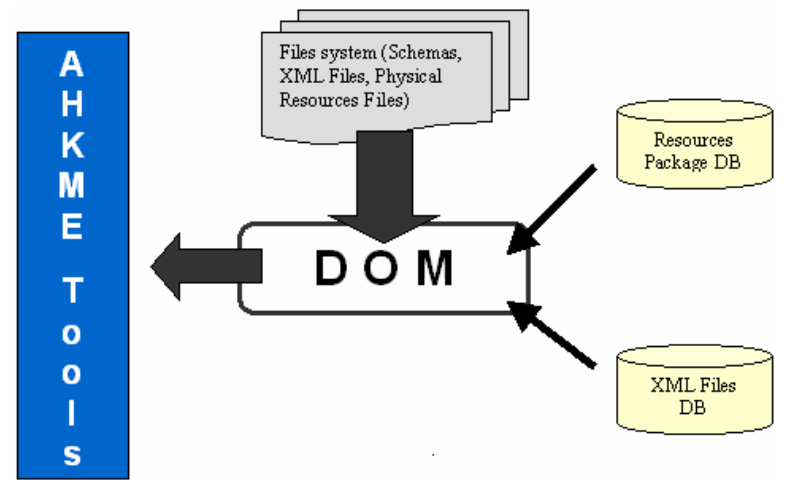

Figure 9. File System/Database and AHKME

\section{CONCLUSIONS}

In this article we've presented how the platform AHKME uses metadata for learning resource management and evaluation.

The IMS specifications, which use the combination of metadata and XML potentialities, are excellent to represent knowledge, dividing information in several meaningful chunks (learning objects) providing their description through metadata and storage in XML files, therefore permitting their cataloguing, localization, indexation, reusability and interoperability, through the creation of information packages. These specifications grant the capacity to design learning units that simultaneously allow users with different roles promoting several types of both collaborative and group learning.

Through knowledge management we have a continuous evaluation of contents, granting quality to all the resources in the platform for teachers and students to use.

AHKME's main contributions are: the learning object management and quality evaluation; the usage of the IMS specifications to standardize all the resources in order to reach interoperability and compatibility of learning components, and the interaction of all subsystems through the feedback between them allowing the platform to adapt to the students and teachers characteristics and to new contexts, using knowledge representation and knowledge management to grant success to the teaching/learning process, being able to be applied in several kinds of matters, students, learning strategies in both training and educational environments.

We aim to go towards the web/e-Learning 3.0 trying to implement the so called semantic web, giving meaning to the resources of the systems, mobility of resources, as well as the universality of learning design, allowing teachers to approach the design process in an intuitive and practical way.

We also try to provide the ability to prepare in practice the semantic web, with tools for creating/customizing specifications and ontologies to convey meaning as well as mechanisms for automatic search by context and adaptive recommendations and add the ability to integrate with other systems such as LMS and social networks by providing them with these features.

Thus, it's very important to have the resources well catalogued, available and with quality to create quality courses, but quality courses don't just depend on quality resources, but also in the design of activities to reach learning objectives.

In terms of future work, we will add the level B of the IMS LD specification in the learning design tool, to include properties and generic conditions. In the adaptive subsystem we will add some functionality according to the IMS Question and Test Interoperability and Enterprise specification. In the knowledge management subsystem we will add the feature of course quality evaluation through the development of some tools.

\section{ACKNOWLEDGMENT}

We would like to thank the GRIAL Research Group of the University of Salamanca. 


\section{REFERENCES}

[1] S. Downes (2005), "E-Learning 2.0”, eLearn Magazine [Online]. Available at: http://www.elearnmag.org/subpage.cfm?article=29$\underline{1 \& \text { section }=\text { articles. }}$.

[2] W3CSW (2009), "Semantic Web Activity", W3 [Online]. Available at: http://www.w3.org/2001/sw/.

[3] M.E.S. Mendes, L. Sacks, "Dynamic Knowledge Representation for e-Learning Applications". In Proceedings of the 2001 BISC International Workshop on Fuzzy Logic and the Internet, FLINT'2001, Memorandum No. UCB/ERL M01/28, University of California Berkeley, USA, Aug., 2001, pp. 176-181.

[4] T. Berners-Lee, J. Hendler, O. Lassila, "The Semantic Web", Scientific American, 284(5), 2001, pp. 34-43. doi:10.1038/ scientificamerican0501-34

[5] M.A. Chatti, M. Jarke, D. Frosch-Wilke, "The future of elearning: a shift to knowledge networking and social software", International Journal of Knowledge and Learning, Vol. 3, Nos. 4/5, 2007, pp. 404-420. doi:10.1504/IJKL.2007.016702

[6] A. Grace, T. Butler, "Learning management systems: a new beginning in the management of learning and knowledge", International Journal of Knowledge and Learning, Vol. 1, No. 1/2, 2005, pp. 12-24. doi:10.1504/IJKL.2005.006248

[7] Myspace (2009) [Online]. http://www.myspace.com/.

[8] Twitter (2009) [Online]. http://twitter.com/.

[9] Facebook (2009) [Online]. http://www.facebook.com/.

[10] Orkut (2009) [Online]. http://www.orkut.com/.

[11] Allan Cho (2008), "What is Web 3.0? The Next Generation Web: Search Context for Online Information" [Online]. Available at: http://internet.suite101.com/article.cfm/what_is_web_30.

[12] S. Wheeler (2009), "Learning with 'e's - e-Learning 3.0" [Online]. Available at: http://steve-wheeler.blogspot.com/2009/04/learning30.html.

[13] ADL. "Sharable Content Object Reference Model (SCORM) ${ }^{\circledR}$ 2004 3rd Edition - Overview Version 1.0", Advanced Distributed Learning, 2006.

[14] IMS Specifications (2004), IMS Global Learning Consortium, Inc.[Online].Available at: http://www.imsglobal.org.

[15] G. Totkov, C. Krusteva, N. Baltadzhiev, "About the Standardization and the Interoperability of E-Learning Resources", CompSysTech'2004 - International Conference on Computer Systems and Technologies, Bulgaria, 2004.

[16] Dublin Core Metadata Initiative (2005). [Online]. Available at: http://dublincore.org.

[17] D. Wiley, "Connecting learning objects to instructional design theory", in D. Wiley (Ed.): The Instructional Use of Learning Objects, 2003.

[18] IEEE LTSC Working Group 12, "Draft Standard for Learning Object Metadata", Institute of Electrical and Electronics Engineers, Inc, 2002.

[19] C. Smythe, A. Jackl, "IMS Content Packaging Information Model - Version 1.1.4 Final Specification", IMS Global Learning Consortium, Inc., 2004.

[20] M. Andric, V. Devedzic, W. Hall, L. Carr, "Keywords linking method for selecting educational web resources a la ZigZag", International Journal of Knowledge and Learning, Vol. 3, No.1, 2007, pp. 30 - 45. doi:10.1504/IJKL.2007.012599

[21] L. Petrides, L. Nguyen, C. Jimes, A. Karaglani, "Open educational resources: inquiring into author use and reuse", International Journal Of Technology Enhanced Learning, Vol. 1, Nos. 1/2, 2008, pp. 98-117. doi:10.1504/IJTEL.2008.020233

[22] P. Barker, L.M. Campbell, A. Roberts, C. Smythe, "IMS Metadata Best Practice Guide for IEEE 1484.12.1-2002 Standard for Learning Object Metadata - Version 1.3 Final Specification", IMS Global Learning Consortium, Inc., 2006

[23] R. Koper, B. Olivier, T. Anderson, "IMS Learning Design Information Model - Version 1.0 Final Specification", IMS Global Learning Consortium, Inc., 2003.
[24] S. Graf, B. List, "An Evaluation of Open Source E-Learning Platforms Stressing Adaptation Issues", ICALT 2005 - The 5th IEEE International Conference on Advanced Learning Technologies, 2005.

[25] J. Vargo, J.C. Nesbit, K. Belfer, A. Archambault, "Learning object evaluation: computer-mediated collaboration and inter-rater reliability", International Journal of Computers and Applications, 25 (3), 2003.

[26] T. Bates (2006), "Strategies for the future" [Online]. Available at: http://bates.cstudies.ubc.ca/strategies.html.

[27] E. Morales, F.J. García, T. Moreira, H. Rego, A. Berlanga, "Units of Learning Quality Evaluation", In SPDECE 2004 Design (Guadalajara, Spain). CEUR Workshop Proceedings, Vol. 117, 2004 [Online]. Available at: http://ceur-ws.org/Vol-117. ISSN 1613-0073.

[28] C. Smythe, F. Tansey, R. Robson, "IMS Learner Information Packaging Information Model Specification - Final Specification Version 1.0", IMS Global Learning Consortium, Inc., 2001.

[29] C. Smythe, "IMS Learner Information Package Summary of Changes - Version 1.0.1 Final Specification", IMS Global Learning Consortium, Inc., 2005.

[30] P. Brusilovsky, W. Nejdl, "Adaptive Hypermedia and Adaptive Web, M. P. Practical Handbook of Internet Computing", Baton Rouge, USA: Chapman \& Hall/ CRC Press, 2004.

[31] J. Jovanović, "Generating context-related feedback for teachers", International Journal Of Technology Enhanced Learning, Vol. 1, Nos. 1/2, 2008, pp.47-69. doi:10.1504/IJTEL.2008.020230

[32] R. Tomlinson (2006), "Software development for e-learning solutions" [Online]. Available at: http://www.robtomlinson.com/DatabasesIneLearning.aspx.

\section{AUTHORS}

Hugo Rego is a PhD Student in Computer Science at the University of Salamanca, Spain. He works as an IT Specialist on the Polytechnic Institute of Viseu, Portugal. $\mathrm{He}$ is a member of the research GRoup in InterAction and eLearning (GRIAL) of the University of Salamanca (email: hugo_rego05@yahoo.com).

Tiago Moreira is a $\mathrm{PhD}$ Student in Computer Science at the University of Salamanca, Spain. He works as an IT Specialist on the Polytechnic Institute of Viseu, Portugal. He is a member of the research GRoup in InterAction and eLearning (GRIAL) of the University of Salamanca (email: thm@mail.pt).

Erla Morales holds a $\mathrm{PhD}$ in Virtual Learning Environments from the University of Salamanca, Spain. She works as an e-learning expert into the "Virtual University" project at the University of Salamanca, Spain. She is a member of the research GRoup in InterAction and eLearning (GRIAL) of the University of Salamanca University (e-mail: erlamorales@usal.es).

Francisco José Garcia holds a $\mathrm{PhD}$ in Computer Science from the University of Salamanca, Spain. He works as a Professor of the Computer Science Department at the University of Salamanca. He is the Director of the research GRoup in InterAction and eLearning (GRIAL) of the University of Salamanca (e-mail: fgarcia@usal.es).

This work was supported in part by the Ministry of Education and Science as well as FEDER KEOPS project (TSI2005-00960).

Manuscript received February 8th 2010. Published as resubmitted by the authors on May 162010. 